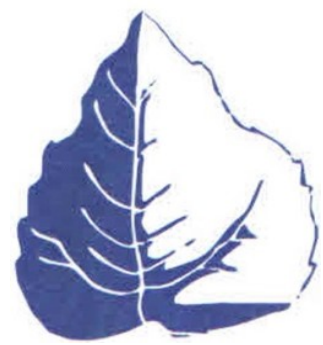

УДК 332.450

\section{ЭКОЛОГИЯ (ПО ОТРАСЛЯМ) ECOLOGY (ITS BRUNCHES)}

https://doi.org/10.23947/2413-1474-2021-5-2-36-42

Мурзин А. Д.

${ }^{1}$ Южный федеральный университет, г. Ростов-на-Дону, Российская Федерация

${ }^{2}$ Донской государственный технический университет, г. Ростов-на-Дону, Российская Федерация

${ }^{3}$ Российский научно-исследовательский институт проблем мелиорации, г. Новочеркасск, Российская Федерация

Исследование характеристик феномена городского развития находится в центре внимания широкого спектра отраслей научного знания на протяжении довольно длительного времени. В рамках данной статьи рассматриваются ключевые взгляды на природу города применительно к различным временным периодам развития урбанистических воззрений. Автором обосновывается целесообразность использования геосистемного подхода к рассмотрению особенностей развития городских поселений. При этом констатируется, что снижение остроты эколого-экономических противоречий, находящих свое проявление в рамках городских геосистем, возможно на основе следования постулатам устойчивого развития.

Ключевые слова: городское развитие, окружающая природная среда, развитие, анализ.

Для цитирования: Мурзин, А. Д. Анализ особенностей и проблем городского развития сквозь призму урбанистических воззрений / А. Д. Мурзин // Экономика и экология территориальных образований. 2021. — T. 5, № 2. — С. 36-42. https://doi.org/10.23947/2413-1474-2021-5-2-36-42

\title{
Analysis of urban development features and problems through the prism of urban views
} Murzin A. D.

${ }^{1}$ Southern Federal University, Rostov-on-Don, Russian Federation

${ }^{2}$ Don State Technical University, Rostov-on-Don, Russian Federation

${ }^{3}$ Russian Research Institute for Melioration Problems, Novocherkassk, Russian Federation

The study of urban development phenomenon characteristics has been the focus of a wide range of scientific knowledge branches for quite a long time. This article examines the key views on the nature of the city in relation to different time periods of the development of urban views. The author substantiates the expediency of using the geosystem approach to the features consideration of urban settlements development. At the same time, it is stated that the reduction of the severity of ecological and economic contradictions that find their manifestation in the framework of urban geosystems is possible on the basis of following the postulates of sustainable development.

Keywords: urban development, natural environment, development, analysis.

For citation: A. D. Murzin Analysis of urban development features and problems through the prism of urban views. Economy and ecology of territorial formations, 2021, vol. 5, no 2, pp. 36-42. https://doi.org/10.23947/2413-1474-2021-5-2-36-42

Введение. В настоящее время, отличающееся все более стремительным развитием урбанизационных процессов, изучение ключевых характеристик города как социально-экономического феномена 
находится в зоне пристального внимания представителей различных научных дисциплин. В этой связи город следует признать объектом, подверженным всестороннему многокритериальному анализу, который имеет место в приложении ко всем существенным статическим и динамически параметрам, определяющим его функционирование как в текущий момент, так и в контексте развития тенденций будущего.

Основная часть. Проанализировав накопленный научной мыслью широкий пласт исследований проблематики городского развития, можно указать на наличие примерно десяти концептуальных точек зрения относительно постулирования сущностного содержания дефиниции «город», они представлены в табл. 1.

Таблица 1

Основные подходы к определению категории «город», присущие различным областям научных знаний

\begin{tabular}{|l|l|}
\hline Наименование подхода & \multicolumn{1}{|c|}{ Ключевые определения } \\
\hline $\begin{array}{l}\text { территориально-поселен- } \\
\text { ческий (географический) }\end{array}$ & $\begin{array}{l}\text { Место концентрированного проживания населения, которое занято ви- } \\
\text { ству деятельности, не имеющими отношения к аграрному производ- }\end{array}$ \\
\hline Социоструктуный & $\begin{array}{l}\text { Место концентрации социальных групп, институтов и их ролевых } \\
\text { функций, которое характеризуется определенными особенностями со- } \\
\text { циальной структуры и социальных отношений }\end{array}$ \\
\hline Социоэкологический & $\begin{array}{l}\text { Ареал антропогенно-естественного взаимодействия элементов, обу- } \\
\text { словливающих функцинирование среды жизнедеятельности человека }\end{array}$ \\
\hline Правовой & $\begin{array}{l}\text { Поселение людей, которому присуща наделенность определенным } \\
\text { юридическим статусом, административными правами, а также наличие } \\
\text { определенного административно-территориального устройства }\end{array}$ \\
\hline Экономический & $\begin{array}{l}\text { Населенный пункт, жители которого в большинстве своем заняты не в } \\
\text { сельскохозяйственной отрасли, а в сервисной и производственной сфе- } \\
\text { рах }\end{array}$ \\
\hline Демографический & $\begin{array}{l}\text { Совокупность людей, характеризующаяся определенными уровнями } \\
\text { распределения населения по полу и возрасту, семейному положению, } \\
\text { национальности и другим признакам }\end{array}$ \\
\hline Системный & $\begin{array}{l}\text { Поселенческая единица, которая реализует специализированные функ- } \\
\text { ции по отношению к общине более высокого территориального уровня }\end{array}$ \\
\hline Фуциокультурный & $\begin{array}{l}\text { Индивидуально-личностная среда реализации творческого потенциала } \\
\text { населения, обеспечения его личностного роста и социального ком- } \\
\text { форта } \\
\text { стемная, структурно целостная и относительно самостоятельная си- } \\
\text { сти таких ее подсистем, как экономическая, социальная, правовая, де- } \\
\text { мографическая }\end{array}$ \\
\hline
\end{tabular}

Истоки возникновения вышеперечисленных и целого ряда других подходов восходят к исследованиям середины XIX века, когда процессы ускоряющегося городского развития заставили исследователей обратить на них пристальное внимание. Собственно, к этому времени относится возникнове- 
ние первых научных определений дефиниции «город», во главу которых ставилось наличие специфичных для городских поселений социальных и экономических условий, порождаемых постоянным взаимодействием большого числа индивидов [1].

Парадигма исследования процессов городского развития, относящихся к первой половине $\mathrm{XX}$ века, заключалась в констатации сущностной природы городских поселений как достаточно сложных социальных организмов, интегрирующих в целостную форму проживающих на его территории индивидов и материальную инфраструктуру и исполняющих функции центров цивилизационного развития.

Вторая половина $\mathrm{XX}$ века ознаменовалась настоящим бумом городских исследований, приведших, в частности, к формированию такой самостоятельной научной дисциплины, как городская антропология, которая ставит своей целью осмысление роли городов в трансформации современного общества.

Французский исследователь М. Доган констатирует, что такая область научного синтеза, как городские исследования, благодаря междисциплинарному обмену концептами, методами, теориями, практиками, инструментарием сейчас является самостоятельной специальностью. Она включает в себя субполя, которые охватывают области социологии, географии, антропологии. При этом социологи и географы оказались особенно успешными в субполе «человеческая экология», тогда как историки — в теоретизации своих построений благодаря заимствованию социологических концептов (структура, функции, социализация, модернизация, социальная мобильность и т. д.) [2].

Интегрируя концептуальные позиции, высказываемые представителями различных подходов к определению ключевых сущностных черт, присущих городским поселениям, мы имеем возможность выделить следующие важнейшие черты, присущие городам на современном этапе их развития:

- наличие застроенной территории, диверсифицированной по своему назначению и привлекательной для организации хозяйственной деятельности и обеспечения проживания населения;

- организация насыщенного элементами социальной инфраструктуры пространства, способного эффективно воспринимать широкий круг социально-экономических инноваций;

- концентрация на городской территории большого количества административных, производственных и социально-культурных объектов;

- обеспечение ориентации на приоритетное развитие образовательных, научных, культурных, информационных и других креативных направлений деятельности горожан;

- расширение зон функционирования и степени влияния финансово-экономических структур, обеспечивающих повышение уровня бизнес-активности и эффективности системы городского хозяйства;

- проявление синергизма в развитии городского пространства, обеспечивающего наличие коммуникативного и интерактивного эффектов городской среды.

При этом большинство подходов к анализу особенностей городского развития в конце XX начале XXI века сосредоточили внимание на неоднозначности урбанизационных процессов, приносящих с собой не только технические и технологические усовершенствования, но и новые угрозы окружающей среде, историко-культурному наследию, затрудняющих обеспечение безопасности жизнедеятельности населения.

Важнейшее свойство города - динамизм, который влияет на образ города, ритм жизни и характер его жителей. Ускоренный темп жизни в процессе развития городов определяется общественными потребностями. Однако вследствие этого ускоренного ритма развития города становятся центрами противоречий, важнейшие из них возникают между потребностями расширяющейся градообразующей базы и ограниченными ресурсами городского пространственного развития, а также между необходимостью развития городского хозяйства и оказываемым в данном процессе негативным воздействием на состояние окружающей среды.

Так, следствием роста численности городского населения является необходимость задействования новых ресурсных возможностей для обеспечения ускорения экономического развития, что, в 
частности, ведет к истощению ресурсного потенциала планеты и изменению климата. Уже в настоящее время в целях энергообеспечения городских поселений используется 78\% мировых запасов энергоносителей, что провоцирует образование почти $80 \%$ совокупного объема парниковых газов [3].

Кроме того, процессы развития городов как формы расселения и территориальной организации производства обуславливают формирование значительного числа социальных противоречий.

Комплекс взаимодействий, существующих в рамках социо-эколого-экономической системы городской территории, может быть представлен следующим образом (рис. 1).

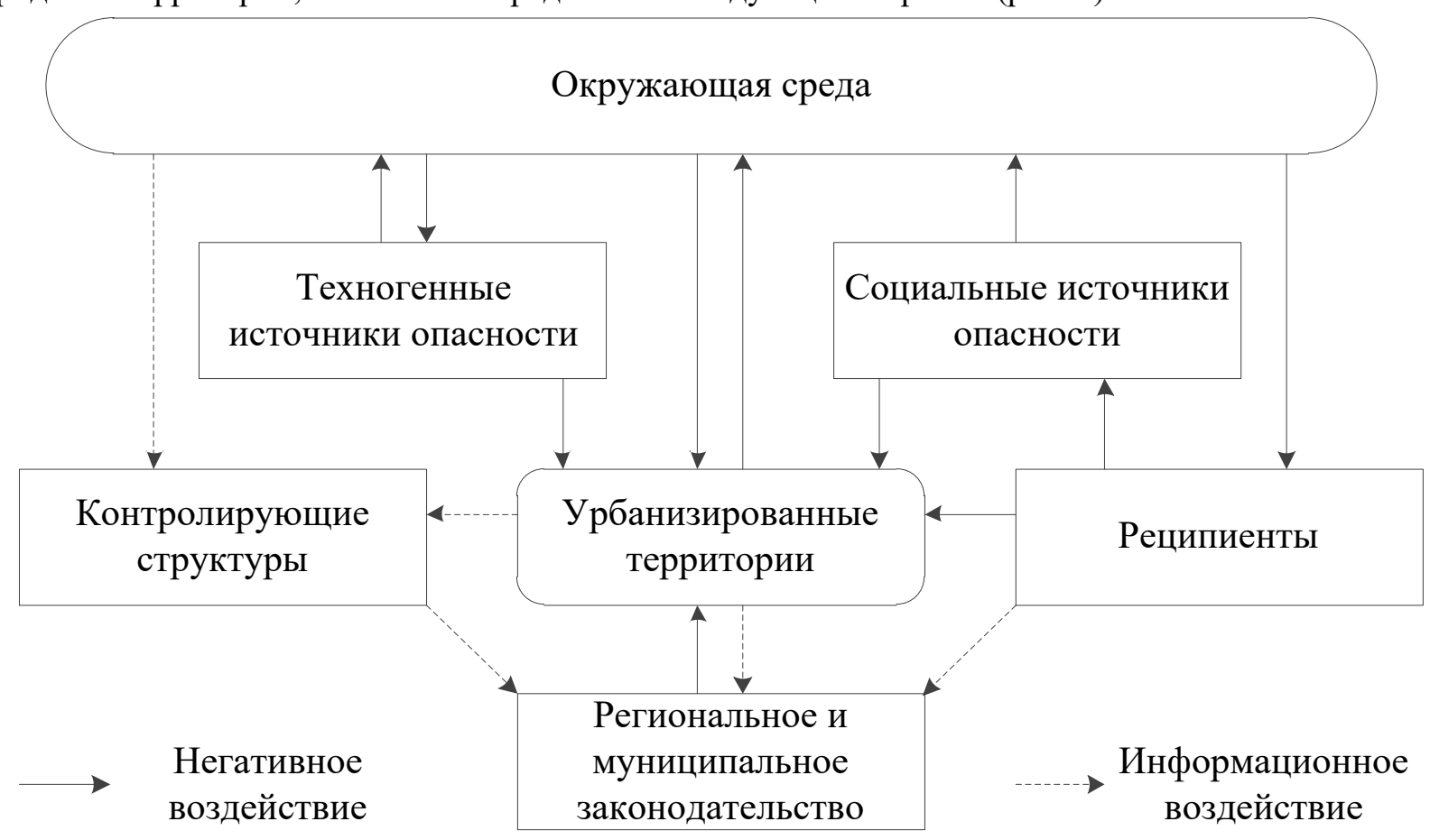

Рис. 1. Механизмы взаимодействия ключевых элементов социо-эколого-экономической системы городской территории

Таким образом, одной из ключевых качественных характеристик современного города является его способность под воздействием аккумулированных положительных и негативных последствий реализуемой на его территории социально-экономической деятельности качественно преобразовывать природную среду и ее компоненты [4].

При этом необходимо отметить, что городские системы являются многофакторными и многокомпонентными структурами, функционирующими и развивающимися благодаря взаимному переплетению многочисленных процессов, проистекающих в их рамках. Данные обстоятельства затрудняют построение адекватных аналитических моделей, а описание городских систем на современном этапе научного познания производится с применением разного уровня допущений и абстракций [5]. Однако даже в этом случае наибольшее внимание уделяется выявлению ключевых тенденций развития данных систем, анализу основных компонентов, формирующих их структуру, и оценке параметров, отражающих различные аспекты функционирования городских систем.

В данном контексте крайне важно отметить, что любой современный город представляет собой уникальное сочетание природно-геологических особенностей месторасположения и населяющих его жителей, образовавшееся под воздействием определенных исторических социокультурных факторов и развивающееся в русле текущих социально-экономических тенденций, что позволяет определить наличие на городских территориях системообразующих элементов, формирующих социо-эколого-экономическую геосистему как динамическую материальную систему, которую составляют географические компоненты, взаимосвязанные и взаимообусловленные в своем развитии и пространственном размещении (рис. 2). Управляющую и преобразующую функции в рамках указанной системы выполняет 
урбо-социальная среда, включающая в себя в качестве составных элементов психолого-социальный, технико-технологический и духовно-культурный блоки.

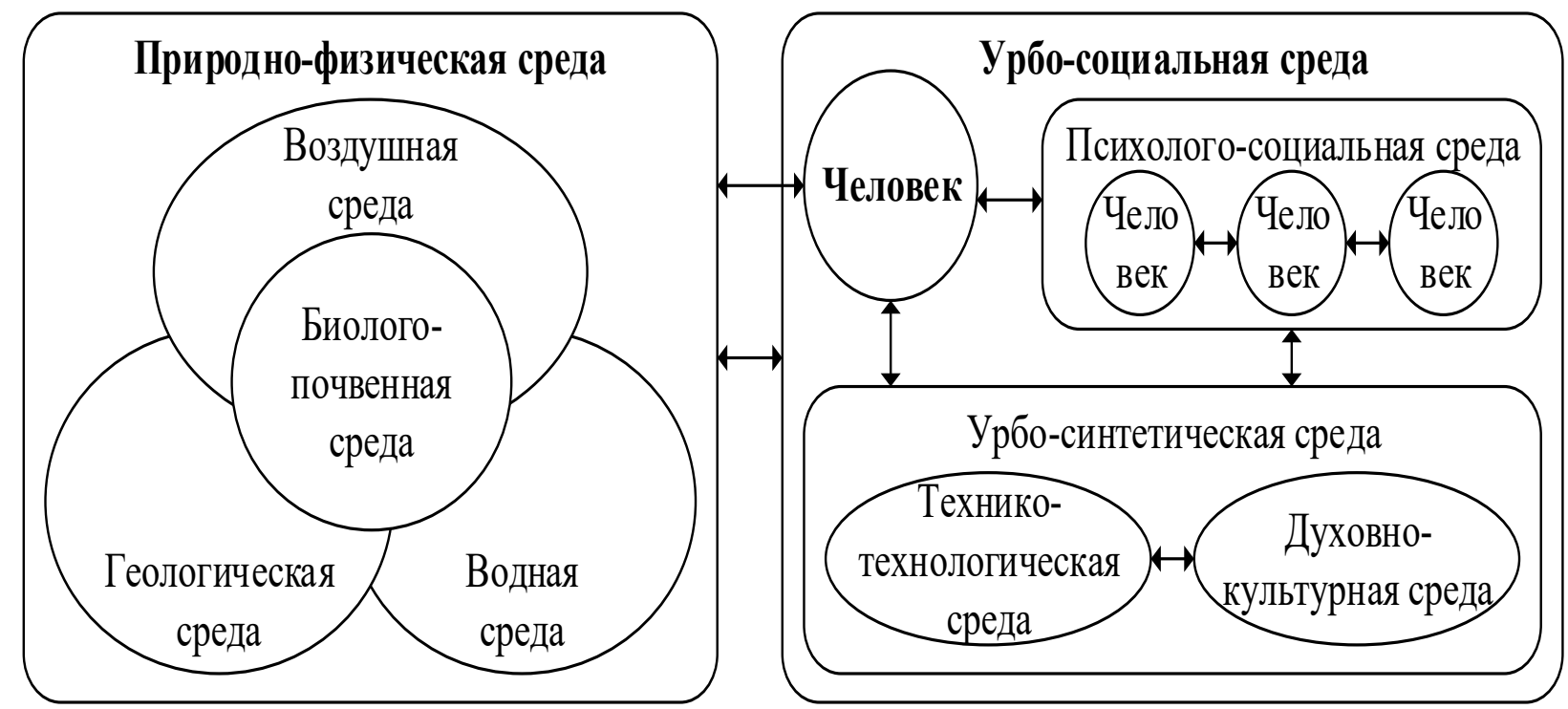

Рис. 2. Составляющие социо-эколого-экономической геосистемы современного города

Одним из основоположников подхода, позволяющего рассматривать города в качестве геосистем, стал Р. Форман, который в своей книге «Мозаика Земли» предложил новую терминологию, инструментарий и методический аппарат для описания и анализа городских экосистем и установил, как ландшафтная структура влияет на развитие территории и проживающих в ее рамках людей [6].

При этом к числу специфических особенностей социо-эколого-экономических геосистем, обуславливающих возникновение целого ряда противоречий, которые в определенной степени препятствуют обеспечению их эффективного развития, можно отнести следующие:

- функционирование социо-эколого-экономических геосистем носит многоаспектный характер, так как оно определяется, как минимум, четырьмя векторами развития - экономическим, социальным, экологическим и территориальным;

- зачастую наблюдается противоречивость интересов органов управления геосистемой и хозяйствующих субъектов, которые функционируют в ее рамках;

- обеспечение эффективного функционирования геосистемы предполагает принятие управленческих решений на основе анализа очень больших объемов разноплановой информации о положении дел как внутри системы, так и в ее внешней среде.

Нивелирование этих противоречий становится возможным в рамках реализации парадигмы устойчивого городского развития, в основу которой положены следующие ориентиры пространственной организации общественных отношений, которые определены Международной комиссией по окружающей среде и развитию: жителей;

- формирование социальных и экономических возможностей для обеспечения благосостояния

- повышение ресурсоэффективности городского развития;

- обеспечение экологической безопасности и рационального природопользования;

- оптимизация учета экономических и экологических интересов.

Заключение. Таким образом, внедрение концепции устойчивого развития на городском уровне не только позволяет решить или, по крайней мере, существенно снизить значимость эколого-экономических противоречий, но и способствует созданию возможностей для выхода на качественно новый 
уровень социально-экономического, демографического и технологического развития городских территорий [7].

При этом организация управления городской территорией в рамках подобного подхода предполагает рассмотрение ее в качестве социо-эколого-экономической геосистемы, ключевым ресурсом которой является совокупность природного, человеческого и экономического потенциалов развития данной территории.

\section{Библиографический список}

1. Вебер, М. История хозяйства : Город / М. Вебер. — Москва : Канон-пресс-Ц : Кучково поле, 2001. $-574 \mathrm{c}$.

2. Доган, М. Социология среди социальных наук / М. Доган // Социологические исследования. - 2010. — № 10 (318). - С. 3-13.

3. Киселева, Е. А. Инновационные технологические решения, применяемые для энергоресурсосбережения в системах городской инфраструктуры / Е. А. Киселева // Вестник МГСУ. — 2011. № 8. - C. 343 .

4. Мусихина, Е. А. Теоретикометодологические аспекты изучения урбанизированных территорий / Е. А. Мусихина, И. В. Ивашкина // Экология урбанизированных территорий. — 2013. — № 1. — C. 10 .

5. Разумов, Р. В. Типология моделей урбанонимических систем Российской Федерации / Р. В. Разумов // Вестник Костромского государственного университета. - 2016. - Т. 22, № 4. C. 123.

6. Forman R. Land Mosaics: The Ecology of Landscapes and Regions. Cambridge: Cambridge University Press, 1995.

7. Ewers H., Nijkamp P. Urban sustainability. Avebury: Gower, 1990. P. 8-10.

Поступила в редакцию 10.03.2021

Запланирована в номер 25.04.2021

\section{Об авторе:}

Мурзин Антон Дмитриевич, зам. декана факультета управления по науке Южного федерального университета (344006, РФ, г. Ростов-на-Дону, ул. Б. Садовая, 105/46), Донской государственный технический университет (344003, РФ, г. Ростов-на-Дону, пл. Гагарина, 1), Российский научно-исследовательский институт проблем мелиорации (346400, РФ, г. Новочеркасск, пр. Баклановский, 190), кандидат экономических наук, доцент, admurzin@sfedu.ru

\section{References}

1. Veber M. Istoriya hozyajstva [History of the farm]. Moscow, Kanon-press-C, Kuchkovo field, 2001:574. (In Russ.)

2. Dogan M. Sociologiya sredi social'nyh nauk [Sociology among the social sciences]. Sociological research, 2010;10;318:3-13. (In Russ.)

3. Kisileva EA. Innovacionnye tekhnologicheskie resheniya, primenyaemye dlya energoresursosberezheniya $\mathrm{v}$ sistemah gorodskoj infrastruktury [Innovative technological solutions used for energy saving in urban infrastructure systems]. Bulletin of MSBU, 2011;8:343. (In Russ.)

4. Musikhina EA., Ivashkina IV. Teoretikometodologicheskie aspekty izucheniya urbanizirovannyh territorij [Theoretical and methodological aspects of urbanized territories study]. Ecology of urbanized territories, 2013;1:10. (In Russ.)

5. Razumov RV. Tipologiya modelej urbanonimicheskih sistem Rossijskoj Federacii [Typology of urbanonymic systems models of the Russian Federation]. Bulletin of Kostroma State University, 2016;22;4:123. (In Russ.) 
6. Forman R. Land Mosaics: The Ecology of Landscapes and Regions. Cambridge: Cambridge University Press, 1995.

7. Ewers H., Nijkamp P. Urban sustainability. Avebury: Gower, 1990:8-10.

Received 10.03.2021

Scheduled in the issue 25.04.2021

\section{Author:}

Murzin Anton D. sub-dean, the department of science, Southern Federal University, (105/46, Sadovaya str., Rostov-on-Don, RF, 344006) Don State Technical University (1, Gagarina sq., Rostov-on-Don, RF, 344003) Russian Research Institute for Melioration Problems, (190, Baklanovskiy av., Novocherkassk, RF, 346400) candidate of economic Sciences, associate Professor, admurzin@sfedu.ru 